Vesna Ristanović ${ }^{1}$, Roksanda Stojanović

\title{
KLINIČKE KARAKTERISTIKE OBOLELIH OD SISTEMSKOG ERITEMSKOG LUPUSA U ZLATIBORSKOM OKRUGU
}

\begin{abstract}
Apstrakt: Sistemski eritemski lupus (SLE) je autoimuna bolest koja se karakteriše multisistemskim ispoljavanjem i serološkim nalazom mnogobrojnih autoantitela. Svaki organ može biti zahvaćen: koža, zglobovi, seroze: pleura, perikard, peritoneum, bubrezi, CNS i hematopoezno tkivo. U etiopatogenezi bolesti, pored genetske predispozicije, važnu ulogu igraju hormonski činioci i spoljašnji etiološki faktori. Uzajamnim dejstvom pokreće se sistem autoimunosti sa hiperreaktivnošću B limfocita koji produkuju autoantitela, najznačajnija su ANA At koja sa Ag grade imune komplekse koji se talože i aktiviraju sistem komplementa i započinju proces zapaljenja i oštećenja različitih tkiva i organa.

Cilj rada je ispitivanje kliničkih manifestacija i laboratorijskih parametara u početnom i ispoljenom SEL kod bolesnika registrovanih u Zlatiborskom regionu. Ispitivanje je sprovedeno u vidu retrospektivne studije i studije preseka. Obuhvaćeno je 60 bolesnika, izvori podataka su ambulantni i hospitalni registri bolesnika sa SEL lečenih u ZC Užice i referentnim ustanovama u Beogradu. Analizirano je vreme i mesto postavljanja Dg, broj ispoljenih dijagnoznih kriterijuma, kliničke, laboratorijske i imunoserološke manifestacije. Upitnik je imao 175 pitanja, korišćen je INDEX aktivnosti ECLAM i INDEX oštećenja SLICC/ACR DAMAGE INDEX.
\end{abstract}

Ključne reči: sistemski eritemski lupus, kliničke karakteristike, tok i ishod.

\section{Uvod}

Sistemski eritemski lupus (SLE) je autoimuna bolest koja se karakteriše multisistemskim ispoljavanjem i serološkim nalazom mnogobrojnih autoantitela. Svaki organ može biti zahvaćen: koža, zglobovi, seroze: pleura, perikard, peritoneum,

Opšta bolnica Užice, Odeljenje za reumatologiju. 
bubrezi, CNS, hematopoezno tkivo. „Lupus“, latinski vuk, korišćen je u 18. veku jer su promene na koži ličile na ugriz vuka.

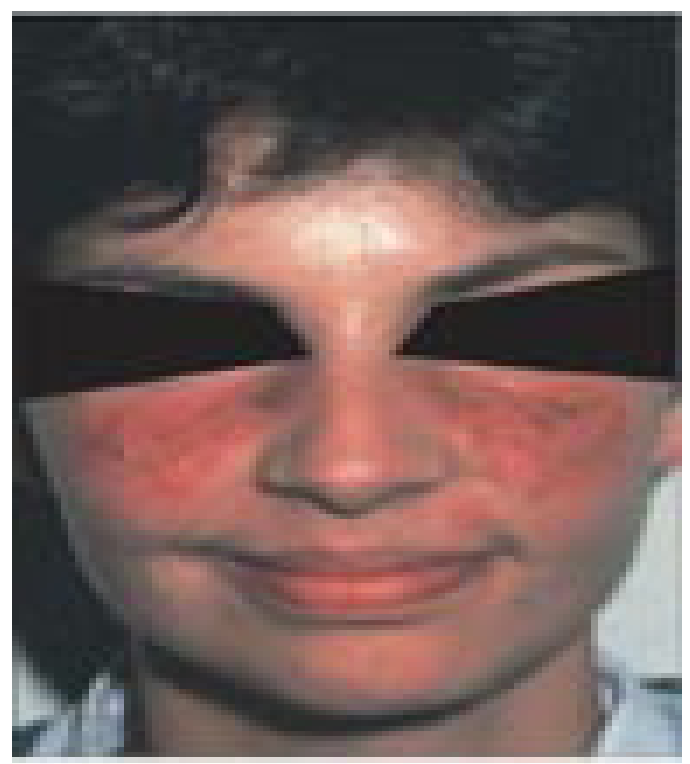

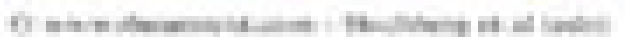

Etiopatogeneza SLE- $a$

Etiološki činioci su:

- Genetska predispozicija (HLA DR2, -DR3)

- Hormonski činioci: smanjen nivo andogena i izmenjen metabolizam estrogena - hiperestrogenemija

- Spoljni etiološki faktori: infekcijski agensi, UV zraci sunca, neki lekovi...

Hiperreaktivnošću B limfocita stvaraju se organ nespecifična ANA At, koja aktiviraju sistem komplementa, kao i organ specifična At, koja izazivaju hemoliznu anemiju, trombocitopeniju, antifosfolipidni sy, lezije CNS-a, kongenitalni srčani blok, uz indukciju od strane „helper“ $\mathrm{T}$ limfocita (Th, CD4+) uz prevagu Th2.

\section{Autoantitela u SLE}

Anti-ds DNK 40-80\%-nefritis

Novootkrivena At:

Anti-ss DNK 90\%

- Annexin V

Anti-DNP 60-75\%

- APO-1 
Antihistonska $30-40 \%$ - izaz. lekom

Anti-Ro(SS-A) 35-60\% - fotos.derm, pluća, neon. lupus

$-\mathrm{C} 1$ inhibitor

Anti-La(SS-B) $15 \%$

$-\mathrm{Clq}$

Anti-U1 RNP / - Raynaud fenomen

$-\mathrm{CD} 36$

Anti-Sm $15-30 \%$ - CNS

$-\mathrm{CD} 45$

Anti-P $10-20 \%$ - psihoza

- collagen tip II

RF $30 \%$

- Fibronektin

APL/aCL 30-40\% - antifosfolipidni sindrom

- Golgi kompleks

Antieritrocitna $10-50 \%-$ Coomb + anemija

$-\mathrm{CD} 4$

Antitrombocitna $<10 \%$ - trombocitopenija

Antilimfocitna $>50 \%$ - lupus CNS

Antineuronska 40\% - difuzni lupus CNS

\section{Učestalost ispoljavanja kliničkih manifestacija}

$$
\text { evr. gr. 704(\%) naši bol. 114(\%)* }
$$

$\begin{array}{lrr}\text { artritis-artralgije } & 94 & 92 \\ \text { kožna ospa } & 69 & 73 \\ \text { leukocitopenija } & 54 & 29 \\ \text { anemija (sve vrste) } & 50 & 48 \\ \text { Raynaudov fen. } & 49 & 43 \\ \text { serozitis } & 44 & 42 \\ \text { nefritis } & 38 & 45 \\ \text { alopecija } & 43 & 44 \\ \text { kožni vaskulitis } & 31 & 27 \\ \text { enantem } & 28 & 20 \\ \text { promene CNS-a } & 26 & 11 \\ \text { Sjogrenov sy } & 25 & 6 \\ \text { tromboze } & 15 & 21 \\ \text { spontani pobačaji } & 10 & 16 \\ \text { periferna neurop. } & 8 & 11\end{array}$

Petrovic R. Doktorska disertacija 1995. g.

Klasifikacioni kriterijumi za SLE (ACR 1982, izmenjeni 1997)

Eritem obraza

Diskoidni lupus

Fotosenzitivnost 
Oralne ulceracije

Neerozivni artritis

Pleuritis ili perikarditis

Bubrežni poremećaji: perzistentna proteinurija veća od $0,5 \mathrm{~g}$ dnevno, ćelijski cilindri.

Neurološki poremećaji: Epi ili psihoza

Hematološki poremećaji: hemolizna anemija ili leukocitopenija/limfocitopenija, ili trombocitopenija

Imunološki poremećaji: anti DNK At ili anti Sm ili antifosf. At: IgG ili IgM antikardiolipinska At, poz. Lupus antikoagulans, lažno pozitivan serološki test za sifilis (VDRL) min. 6 meseci

Pozitivna antinukleusna antitela

\section{Cilj rada}

Ispitivanje kliničkih manifestacija i laboratorijskih parametara u početnom i ispoljenom SLE

\section{Ispitanici i metode rada}

Sprovedena su retrospektivna studija i studija preseka na 60 bolesnika. Izvodi podataka su ambulantni i hospitalni registri bolesnika sa SLE u zlatiborskom okrugu lečenih u ZC Užice i referentnim ustanovama.

Registrovano je: vreme i mesto postavljanja Dg, broj ispunjenih dijagnoznih kriterijuma, kliničke, laboratorijske i imunoserološke manifestacije pri postavljanju dg i pri pregledu.

Upitinik za bolesnike sadrži 175 pitanja sa: identifikacionim i demografskim podacima, kliničkim manifestacijama pri postavljanju Dg i pri pregledu, kliničke simptome i znake u vreme postavljanja dijagnoze i pri pregledu, laboratorijske i imunoserološke analize, radiografije, ehokardiografije, DEXA i MRI ispitivanja.

\section{Rezultati}

- Demografska obeležja ispitanika pol: muški 3 (5\%), ženski 57 (95\%), odnos 1: 19 zanimanje: služ. 4 (6,7\%), dom. $23(38,3 \%)$, penz. $5(8,3 \%)$, invalid $11(18,3 \%)$, umerena fiz. akt. $14(23,35)$, student $3(5,0 \%)$ 
mesto stanovanja: selo 18 (30\%), grad $42(70 \%)$

stručna sprema: osnovna 27 (45\%), SSS $25(41,7 \%)$, viša $1(1,7 \%)$, visoka $7(11,7 \%)$

- Deskriptivna analiza

Starost pri prvim simp.:

starost pri post. dg:

dužina trajanja bolesti:

broj ispunjenih kriter:

broj štetnih efek. KS Th:

broj štet. efek. citost. Th:

ECLAM:

Index oštećenja:

min. $12 \mathrm{~g}$, max $63 \mathrm{~g}$, srednja vred. $37,5 \mathrm{~g}$, $\min 13 \mathrm{~g}$, max $63 \mathrm{~g}$, srednja vred. $38 \mathrm{~g}$, $\max 28 \mathrm{~g}$, srednja vred. $9 \mathrm{~g}$, $\min 4, \max 7$, srednja vred. 5,5 , $\min 0, \max 4$, srednja vred. 2 , $\min 0$, $\max 3$, srednja vred. 1 , min. 1 , max 8 , srednja vred. 4,5 , min. 0 , max 7 , srednja vred. 3,5 .

Dijagnoza je postavljena u O. B. Užice kod 14 bolesnika (23,3\%), u Institutu za reumatologiju kod 36 bolesnika $(60,0 \%)$ i u Klinici za reumatologiju VMA kod 10 bolesnika (16,7\%).

Broj ispunjenih kriterijuma je bio 4 kod 34 bolesnika (56,7\%), 5 kod 18 bolesnika (30,0\%), 6 kod 6 bolesnika (10,0\%) i sedam kod 2 bolesnika (3,3\%).

\section{Kliničke manifestacije bolesti na početku bolesti i na dan pregleda}

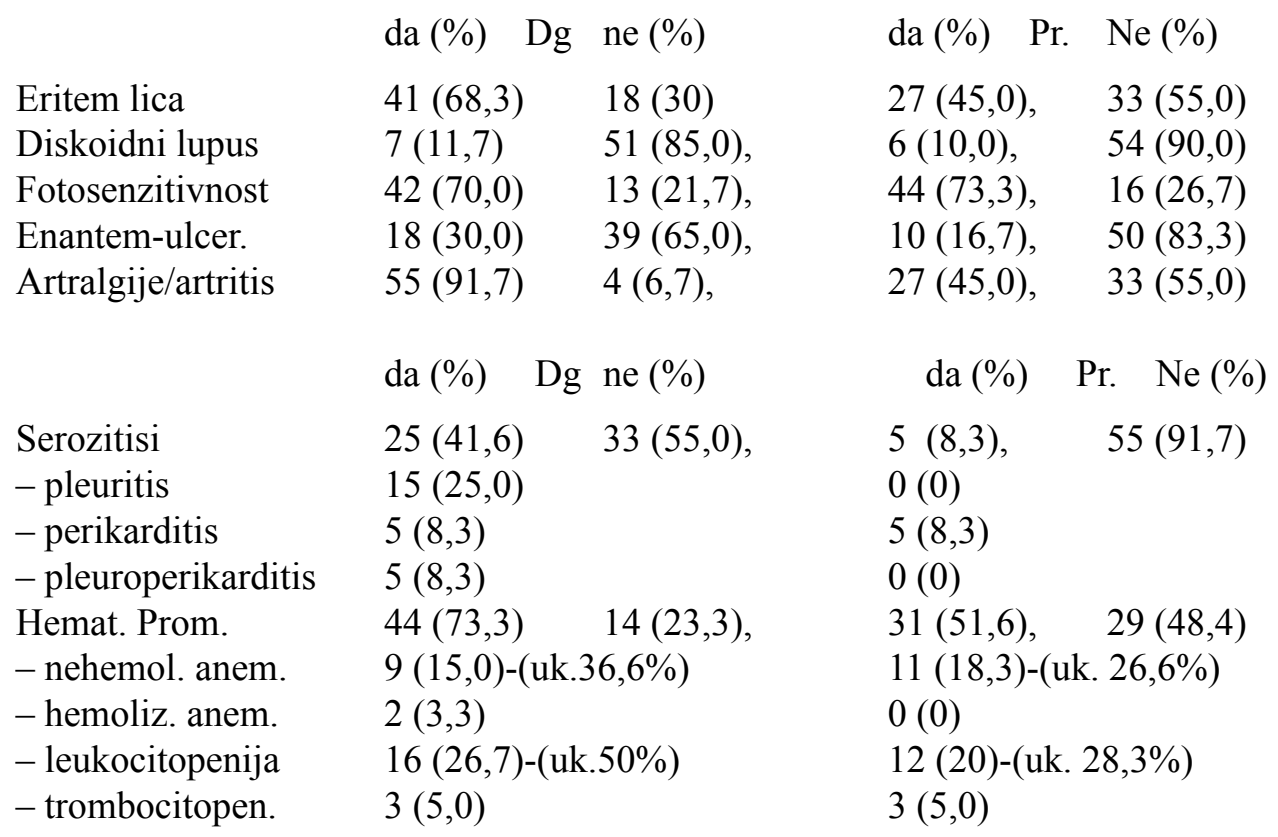


- nehem. + leukoc.

- leukoc. + tromboc

Lezije bubrega
$11(18,3)$

$3(5,0)$

$12(20,0)$
$5(8,3)$

$0(0)$,

$20(33,3), \quad 40(66,7)$

U laboratorijskim rezultatima kod SLE sedimentacija eritrocita (SE) je ubrzana skoro kod svih bolesnika, posebno za vreme aktivne faze bolesti, i veća je od $25 \mathrm{~mm} / 1$ $\mathrm{h}$ mereno po metodi Westergreen. Anemija je česta i može biti posledica osnovne bolesti, otkazivanja bubrega, gubitka krvi, slabe ishrane i zbog imunoloških poremećaja. Anemija je normocitna, normohromna, sa malim brojem retikulocita. Gvožđe u serumu može da bude sniženo pa treba misliti na krvarenje iz GIT-a., Može se razviti hemolitička anemija sa povećanim brojem retikulocita, pozitivnim direktnim Coombsovim testom, što je posledica nastanka „toplih“ IgG antitela. Leukocitopenija se nalazi u velikom procentu bolesnika, ali broj leukocita može biti povećan zbog infekcije i delovanja visokih doza kortikosteroida. Limfocitopenija se nalazi u aktivnoj fazi bolesti. Broj trombocita takđe može biti snižen.

Promene u serumskim belančevinama su poliklonske, ređe monoklonska gamapatija. Kod sumnje na lupus nefritis neophodna je obrada bubrežne funkcije (DU, dnevna proteinurija, klirens kreatinina, serumski kreatinin i elektroliti), kao i merenje krvnog pritiska.

Koncentracije fibrinogena $u$ krvi nije $u$ korelaciji sa aktivnošću bolesti. Reaktant akutne faze u inflamaciji je CRP koji je povišen kada postoji sinovitis, serozitis ili infekcija.

U serumu se mogu dokazati antinukleusna antitela (ANA) po tipu imunoinfluorescencije i visokosenzitivna su jer se nalaze kod $98 \%$ bolesnika sa SLE. Karakteristična antitela su anti ds-DNK i anti Sm-At.

\section{Imunološki pokazatelji pri postavljanju Dg i pri pregledu}

da Dg ne

$19(31,7 \%), \quad 17(28,3 \%)$,
$48(80,0 \%), \quad 5(8,33 \%)$,
$35(58,3 \%)$,
$13(21,7 \%)$,
$21(35 \%)$,
$14(23,3 \%)$,
$7(11,7 \%)$,

$7(11,7 \%)$, da Pr. ne

Le ćelije

ANAAt

- nizak titar

- visok titar

Anti DNK At

$-<55 \mathrm{Ui} / 1$

$->55 \mathrm{Ui} / 1$
$6(10 \%)$

$41(68,3 \%), \quad 7(11,7 \%)$

$20(33,3 \%)$,

$21(35,0 \%)$,

$35(58,3 \%)$

$21(35,0 \%)$

$14(23,3 \%)$

Imunološki pokazatelji su promenljivi tokom lečenja, registrovan je porast titra anti DNK At sa posledičnim ispoljavanjem lupus nefritisa. 


\section{Zbirni grafikon kliničkih manifestacija pri Dg i pri pregledu:}

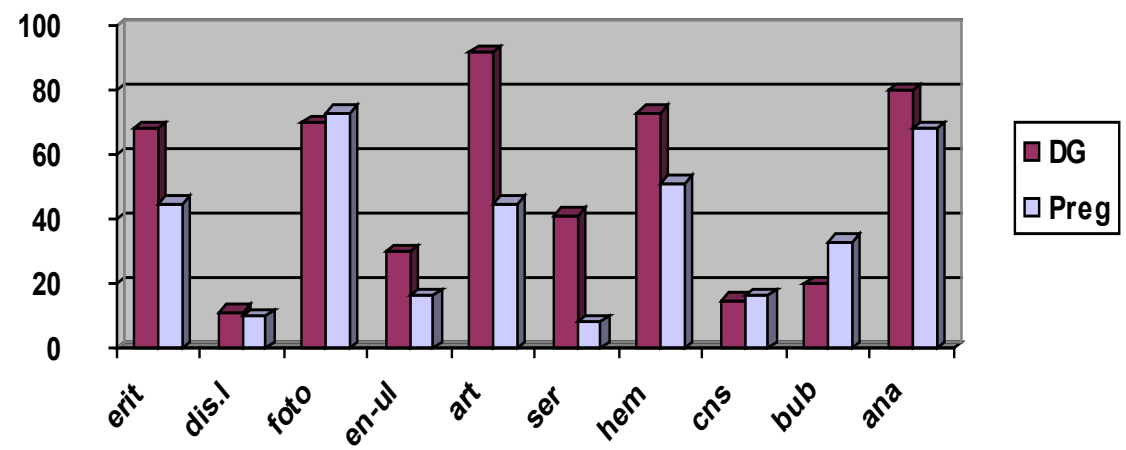

\section{Zaključci:}

- Bolesnici sa SLE ispoljili su najčešće sledeće kliničke manifestacije: fotosenzitivnost, hematološke promene (leukocitopenija), artralgije i artritis, eritem lica, lezije bubrega i CNS-a. Učestalost oštećenja bubrega je rasla tokom trajanja bolesti dok nije bilo promene u učestalosti oštećenja CNS-a.

- Vreme od prvih simptoma do postavljanja Dg bilo je 16 meseci, znatno kraće nego u objavljenim studijama.

- Kod četvrtine bolesnika dijagnoza bolesti je postavljena u regionalnom centru i potvrđena u referentnim ustanovama, a kratko vreme od prvih simptoma do postavljanja dijagnoze ukazuje da su simptomi i znaci SEL rano prepoznati i bolesnici pravovremeno upućeni u referentne ustanove.

- Povoljan tok i ishod SEL kod bolesnika u Zlatiborskom regionu postignut je zahvaljujući odgovarajućoj edukaciji reumatologa, razvijenoj reumatološkoj službi i dobroj komunikaciji regionalnog i referentnih reumatoloških centara.

\section{Reference}

1. Abbas AK. Immuniti to Microbes. In Cellular and Molecular Immunology. Abbas AK, Lichtman AH, Pobes JS. Ed. 341-61. WB Saunder Company 1997.

2. Boumpas DT, Balow JE. Outcome criteria for lupus nephritis trials: A critical overview, Lupus 1998; 7: 622-629.

3. DCruz D, Hughes GRV. Lupus and the nervous system. Lupus 2003; 12: 871.

4. Moss KE, Ioannou Y, Sultan SM et al. Outcome of cohort of 300 patients with systemic lupus erythematosus attending a dedicated clinic for over two decades. Ann Rheum Did 2002; 61: 409-13.

5. Swaak AJG, Van den Brink HG, Smeenk RJT et al. Systemic lupus erythematosus. Disease outcome in patients with a disease duration of at least 10 years: second evaluation. Lupus 2001; 10: 51-58. 